\title{
Chronic constrictive pericarditis associated with toxoplasmosis
}

\author{
N. Nagaratnam and S. J. Stephen \\ From the General Hospital, Colombo, Sri Lanka (Ceylon)
}

A 22-year-old man with pericarditis caused by toxoplasmosis, later progressing to constriction, is presented. The aetiological diagnosis was made on serological studies. The available published reports are briefly reviewed.

Toxoplasma gondii can affect the pericardium as part of a generalized infection (Jones, Kean, and Kimball, 1965) or as an isolated infection (Hakkila, Frick, and Halonen, 1958; Warter et al., 1964). That it can lead to constriction is not clear (Theologides and Kennedy, 1969), but Jones et al. (1965) described such a case.

The clinical course is described in a patient with pericarditis believed to be due to toxoplasmosis, whose progression to constriction prompted us to place the case on record.

\section{Case report}

A 22-year-old man was first seen at the Government Hospital, Gampaha, on 20 May 1971, with breathlessness and cough of 3 months' duration. He had had fever for 3 days and recurrent febrile episodes since the onset of his illness.

Examination revealed a breathless patient who was febrile (temperature $40^{\circ} \mathrm{C}$ ), pulse I2O a minute and irregular. There was no cyanosis. The jugular venous pressure was not raised. There was a pericardial rub over a large area of the praecordium. Both heart sounds were normal and there were no bruits. The lungs were clear. The liver and spleen were not palpable. There was no ascites.

Investigations: WBC $5400 / \mathrm{mm}^{3}, \mathrm{~N} 5 \mathrm{I}, \mathrm{L} 46 \mathrm{E} 3$ per cent, haemoglobin $9.2 \mathrm{~g} / \mathrm{IOO} \mathrm{ml}$, ESR $15 \mathrm{~mm} / \mathrm{hr}$, Mantoux test negative. Electrocardiogram showed atrial fibrillation with non-specific T wave changes. $X$-ray of the chest revealed an enlarged heart shadow with clear lung fields (Fig. a). Haemagglutination test for toxoplasmosis (Jacobs and Lunde, 1957; Kulasiri and Amarasinghe, 1970) was positive at $I / 64$ on 20 May and I/64 on $4 \mathrm{July}$; indirect fluorescent antibody test (Kelen, Ayllon-Leindl, and Labzoffsky, 1962) was positive at
I/32 on 20 May and $1 / 4096$ on 4 July). Haemagglutination inhibition test for arbovirus revealed a fixed group $B$ arbovirus infection indicative of past dengue infection.

He was treated with penicillin and streptomycin. On the 5th day after admission his temperature returned to normal but the pericardial rub continued to be heard until 6 June. An electrocardiogram on II June revealed sinus rhythm and the T waves were less deep. $X$-ray at this stage showed no change in the size of the cardiac shadow. He was sent home on 13 June.

He was seen again at the outpatients on Io August when he was apparently free of symptoms. ESR $6 \mathrm{~mm}$, haemagglutination test $1 / 128$ and indirect fluorescent antibody test $1 / 32$. $X$-ray showed enlargement of the cardiac shadow with basal congestion (Fig. b).

In October 1971 he appeared ill, dyspnoeic, and had a raised jugular venous pressure. There was no cyanosis. The blood pressure was $150 / 100 \mathrm{mmHg}$ and his pulse 80 a minute with pulsus paradoxus. All peripheral pulses were present and of good quality. The area of cardiac dullness was enlarged however; no apex beat was visible or palpable. The cardiac sounds were soft and there were no murmurs. There was ascites and the liver was palpable three fingerbreadths below the right costal margin. The tip of the spleen was palpable and there was oedema of the face. Blood count and blood chemistry were within normal limits. $X$-ray of the chest showed enlargement of the cardiopericardial silhouette, encysted fluid in the right oblique fissure, and pleural effusion in the left base. Electrocardiogram showed sinus rhythm and low voltage $Q R S$ complexes with non-specific $T$ wave changes. Right heart catheterization revealed a raised mean pressure in the superior and inferior vena cava, and right atrium (12 to $15 \mathrm{mmHg}$ ); while the catheter was being introduced into the right ventricle the patient had a cardiac arrest and was revived by external cardiac massage. The catheterization was abandoned.

At operation the chest was exposed by a left thora- 


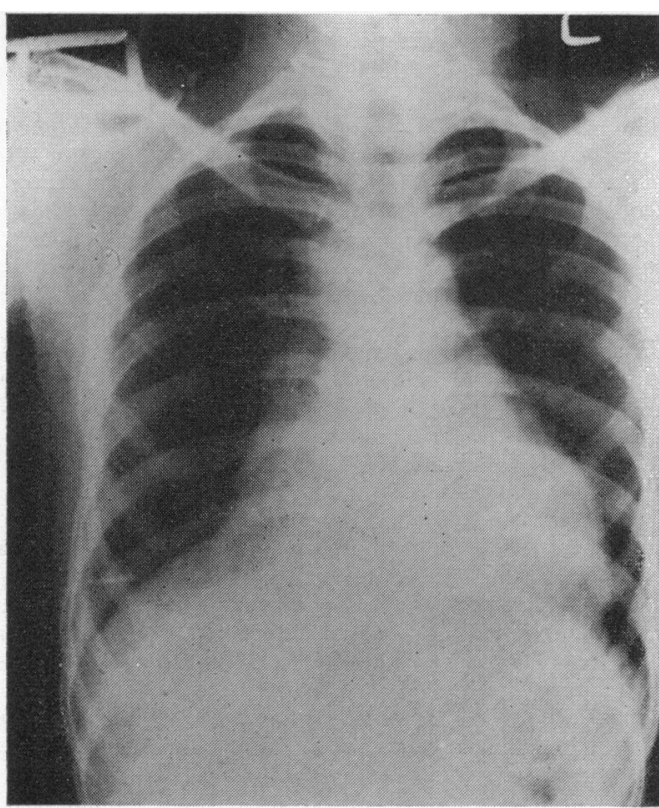

(a)

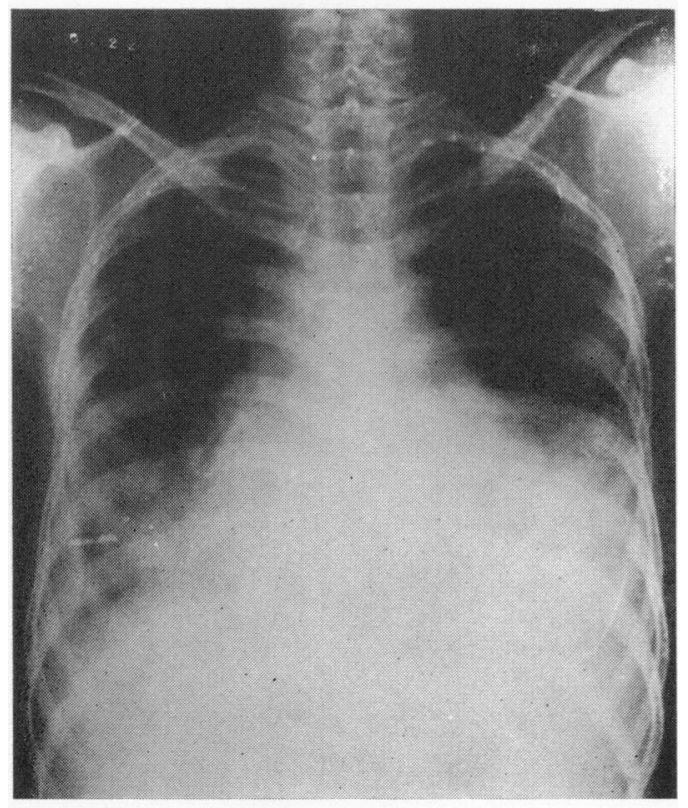

(b)

FIG. (a) X-ray showing enlarged heart shadow (20 May I97I); (b) x-ray showing enlarged heart shadow with basal congestion (Io August I97I). cotomy, through the bed of the fifth rib. The heart was encased in a fibrous, non-pulsatile sac of the pericardium. There was no caseation or calcification. The left ventricle was stripped of the adherent pericardium and then the right. There was no atrioventricular groove constriction. The pericardium over the right ventricle was less adherent than the left. The right ventricular contractions were poor even after the strip. Postoperatively the patient responded well and had no complications. The patient was discharged from the hospital after a month. He continues to do well and has no symptoms 9 months after operation. The chest $x$-ray remains essentially normal.

Histology of the pericardium showed a dense inflammatory infiltrate in a fragment of tissue with occasional granuloma, consisting of epithelioid cells and scanty giant cells, mainly of the foreign body type. The appearance was not typical of tuberculous pericarditis though this possibility could not be ruled out.

\section{Discussion}

A large proportion of cases of chronic constrictive pericarditis has been attributed to tuberculous infection. Less commonly constriction follows pyogenic infections, idiopathic benign pericarditis, Coxsackie $B$ virus infection, and trauma.

In our case even during the active stage of the illness the ESR was normal and the Mantoux was negative, findings against a tuberculous aetiology. Furthermore, the histological appearances of the pericardium were not typical of tuberculous pericarditis. Our patient also had a fixed arbovirus (dengue) antibody titre, evidence of a past infection. This may have had no relation to the pericarditis though arbovirus (dengue) is known to cause pericarditis (Nagaratnam, Siripala, and de Silva, 1973).

The aetiological diagnosis relies mainly on the serological studies for toxoplasmosis. Could the high antibody titres be due to an anamnestic increase in the pre-existing toxoplasma antibodies by another infection, for example tuberculosis ? Such a rise in antibody titres is not known (DeSaram, Kelen, and Labzoffsky 1962). Sabin (1956) recorded a case of a patient with pneumonitis due to histoplasmosis, who, during the course of his illness, showed a rise in the dye titre for toxoplasmosis from $\mathrm{I} / \mathrm{1} 6$ to I/1024. Huldt (1958) recorded high dye titres in patients with tuberculosis.

De Saram et al. (1962) in a study evaluating the reliability of the dye test in the laboratory diagnosis of toxoplasmosis found that in one set of I IO sera obtained from patients with illnesses unrelated to toxoplasmosis but with dye titres ranging from $1 / 16$ to $1 / 1024$ only 15 gave a positive reaction with the other 3 tests, namely complement-fixation test, haemagglutination test, and indirect fluorescent antibody test. Their titres were however very much 
lower than in our case, ranging from $1 / 8$ to $I / 32$, $I / 8$ to $I / 124$, and I/16 to $I / 64$, respectively. In our case there was more than a sixfold rise in the indirect fluorescent antibody. The haemagglutination test is also a sensitive test and specific test for diagnosis, though it appears to be deficient in detecting antibodies in the acute stages of the infection (Prakash, I966).

Jones et al. (1965) described a 24-year-old man with fever, chest pain, and pericardial effusion requiring pericardiotomy. Nine months later he was shown to have pericardial thickening. Antibody titres for Toxoplasma gondii were very high and the organism was isolated from a cervical lymph node. Histology of the pericardial tissue did not show any parasites. When first seen, our patient had been ill for about 3 months and had constriction 6 months later.

We wish to thank Dr. C. Kulasiri, Medical Research Institute, Colombo, for performing the serological tests for toxoplasmosis, Dr. Doris C. Peiris, consultant pathologist, General Hospital, Colombo, for reviewing the histology of the pericardium, and the Director of Health Services, for permission to publish.

\section{References}

DeSaram, W., Kelen, A. E., and Labzoffsky, N. A. (1962). Comparison of serological tests in toxoplasmosis. Canadian Medical Association fournal, 87, 604.
Hakkila, J., Frick, H. M., and Halonen, P. I. (1958). Pericarditis and myocarditis caused by toxoplasma; report of a case and review of the literature. American Heart fournal, $55,758$.

Huldt, G. (1958). The dye test and complement-fixation test in toxoplasmosis: a comparative investigation. Acta Pathologica et Microbiologica Scandinavica, 43, I4I.

Jacobs, L., and Lunde, M. N. (1957). A haemagglutination test for toxoplasmosis. Fournal of Parasitology, 43, 308.

Jones, T. C., Kean, B. H., and Kimball, A. C. (1965). Pericarditis associated with toxoplasmosis. Annals of Internal Medicine, 62, 786.

Kulasiri, C. De S., and Amarasinghe, D. K. C. (1970). Indirect haemagglutination test antibodies against Toxoplasma gondii in cases of lymphademopathy in Ceylon. Ceylon Fournal of Medical Science, 19, 41.

Kelen, A. E., Ayllon-Leindl, L., and Labzoffsky, N. A. (1962). Indirect fluorescent antibody method in serodiagnosis of toxoplasmosis. Canadian fournal of Microbiology, 8, 545 .

Nagaratnam, N., Siripala, K. A., and de Silva, Nandani (1973). Arbovirus (dengue type) as a cause of acute myocarditis and pericarditis. British Heart fournal, 35, 204.

Prakash, O. (1966). Haemagglutination test in suspected cases of toxoplasmosis. Indian fournal of Medical Research, 54, 437.

Sabin, A. B. (1956). Human toxoplasmosis; with special reference to intraocular inflammation: a critical review. American fournal of Ophthalmology, 41, 600.

Theologides, A., and Kennedy, B. J. (1969). Toxoplasmic myocarditis and pericarditis. American fournal of Medicine, 47, 169.

Warter, J., Schwartz, J., Bloch, R., and Schraub, S. (1964). Exist-t-il une péricardite toxoplasmique ? Presse Médicale, 72, 3047.

Requests for reprints to Dr. N. Nagaratnam, the General Hospital, Colombo, Sri Lanka (Ceylon). 